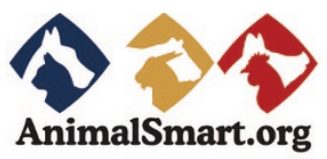

\title{
Engaging the public on animal science
}

The homepage of the AnimalSmart.org website features a cute, bucolic scene of a farm with cows and horses and a chicken on the roof; a veterinary building; a pond with swimming ducks and a Fresh Mart store with a parking lot. A pickup truck with pigs in the back periodically runs through the scene. Only when the visitor reads the small print is it clear that this site is not from an independent organization but is an educational product of the American Society of Animal Science (ASAS).

On Lab Animal's visit to the website, the homepage carried a response to the question 'Why are male swine castrated?' and an invitation to sign up for the Jr. Animal Scientist program. The visuals and simplicity of the site form an obvious appeal to children, although, according to Meghan Wulster-Radcliffe, CEO of ASAS, the site is meant for "consumers' at all levels," with "an emphasis on kids...." And despite the simple, easily readable format, this site is truly for the general public. In an introductory page called 'What are species?', the phylogenetic species concept is explained so clearly that it could be understood by an advanced high school student, a beginning college biology student or any interested member of the public.

And although the emphasis of the site is on livestock, it includes companion animals, fish and animal species used in research. This latter information may be reached through a box on the bottom of the 'What are species?' page and begins with 'Benefits of animal research.' The general statement on benefits, particularly on animal and human health, is crystal clear. It then continues to discuss xenotransplantation, animal behavior and farming, nutritious food and the Animal Welfare Act (AWA).

On the left-hand side of the page is a banner with subheadings, and from the animal research page, one of the highlighted subheadings is 'Animal welfare,' leading to a page called 'Animal welfare defined.' This page focuses mainly on farm animals but introduces the AWA, the concept of an IACUC and enrichment.

The site includes information on diagnosing animal diseases, zoonoses and even 'Animal enrichment in zoos.' As an example of animal enrichment, there is a link to the Gorilla Species Survival Plan (SSP) website. SSPs are programs administered by the Association of Zoos and Aquariums.

There's even a link to a page that gives examples of different careers in animal science, including nutritionist (along with an interview with a zoo nutritionist), physiologist, reproductive physiologist, animal behaviorist, geneticist and animal products scientist. This page alone would be something a high school or community college instructor could flash on a screen to introduce fields many students have never heard of.

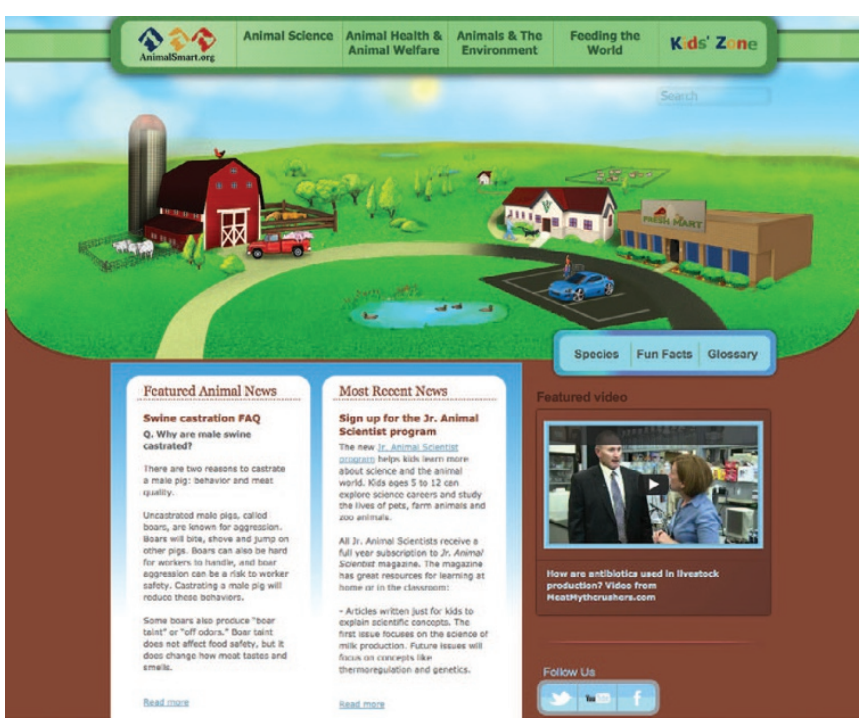

The Jr. Animal Scientist pages are for children ages 5-12 years. Access requires a membership (and permission from a guardian, parent or teacher to join) and members receive special content and a subscription to Jr. Animal Scientist magazine. A sample of the November 2012 issue is available online. Its focus is milk, including what a cow needs to produce it. It contains entertaining fun factsthis reviewer did not know that a cow's daily milk production is sufficient to make enough "mozzarella cheese for 40 pizzas." There's a recipe for making butter from whipping cream and a word search that includes the term 'alveoli' in reference to the udder. In addition to the emphasis on milk, there's an article about a herpetologist! (Note: This reviewer, a herpetologist, was impressed with the site before reading this, and the sponsor of the issue was the University of Connecticut Department of Animal Science creamery. Yum!)

There is also a glossary defining terms such as 'duodenum,' 'embryo transfer' and 'global food security', among many others.

The site, which debuted in summer 2012, will include a Teaching Guide in early 2013. Although Lab Animal's readers are probably well aware of most of the information presented at AnimalSmart. org, it is a terrific site for children and undergraduates. For those who want more complex information about animal science, ASAS's Taking Stock website (http://takingstock.asas.org/) is a better choice-and it has more complicated recipes, besides.

\section{http://animalsmart.org}

Content

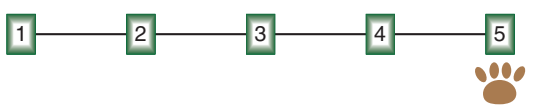

Appearance

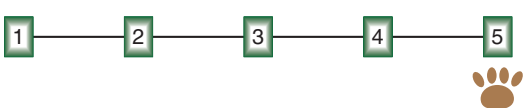

Usability

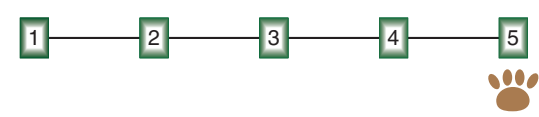

